\title{
Modern Ultrasonographic Techniques in Diagnosing Patients with a High Risk for Preterm Delivery
}

\author{
Arkadiusz Krzyżanowski, Tomasz Gęca, Maciej Kwiatek* and Anna Kwaśniewska \\ Department of Obstetrics and Pathology of Pregnancy, Medical University of Lublin, Poland
}

Submission: December 21, 2017; Published: January 19, 2018

*Corresponding author: Maciej Kwiatek, Department of Obstetrics and Pathology of Pregnancy, Medical University of Lublin, ul. Staszica 1620 085 Lublin, Poland, Tel: 0048 815326612; Email: kwiatula1@wp.pl

\begin{abstract}
Preterm delivery as the main cause of perinatal mortality and morbidity, remains the most important challenge of contemporary perinatology. In this study we present some new ultrasonographic methods in diagnosing women at high risk of preterm delivery. One of them is Three Dimensional (3D) assessment of cervix which allows evaluating uterine cervix simultaneously in three imaging planes: sagittal, transverse and coronal. The Virtual Organ Computer-aided Analysis imaging program (VOCAL) is a software which is integrated into a 3D ultrasound system. It is used to calculate cervical volume and power Doppler flow indices from the multiplanar views of the cervix. The technique allows to calculate vascularization index (VI), flow index (FI) and vascularization flow index (VFI). Elastography is a modern, non-invasive, easy and reproducible method which allows identifying patients with an increased risk of preterm birth in asymptomatic women. At the current stage of knowledge, the techniques mentioned above should be considered experimental and further studies are required to assess the potential of these sophisticated methods in routine clinical practice.
\end{abstract}

Keywords: Preterm labor; Three-dimensional ultrasonography; Cervical length; Volume measurement; Elastography

Abbrivations: FI: Flow Index; VFI: Vascularization Flow Index; 3D: Three Dimensional; VI: Vascularization Index

\section{Introduction}

Preterm delivery remains to be one of the most important challenges of contemporary perinatology. It complicates more than $12 \%$ of pregnancies and is the main cause of perinatal mortality and morbidity [1]. Only 12-27\% from all woman with signs and symptoms of preterm birth (PTB) deliver before 37 weeks of gestation $[2,3]$.

In this article we present new ultrasonographic approaches in diagnosing patients with a high risk for preterm delivery:

a. Two Dimensional (2D) and Three Dimensional (3D) assessment of cervix,

b. Cervical Elastography.

\section{D and 3D assessment of cervix}

One of the best predictors of a true preterm delivery is sonographic assessment of cervical shape and length (CL). The assessment of CL may be approached by transabdominal, translabial or transvaginal routes, with each having its own limitations. The most accurate method to measure CL seems to be transvaginal ultrasound (TVU), which has greater interobserver reliability than standard digital examination of the cervix $[4,5]$. The proper measurement of CL begins at the internal os of the cervix, follows the path through the endocervical canal, and ends at the external os. In the case of curved cervical canal, it can be measured by tracing or summing up two straight lines that follow the curve [6]. An appropriate technique of measuring CL during TVU, adapted from Berghella and Bega is presented below [7]:

a. Have the woman empty her bladder just before ultrasound.

b. Prepare the clean probe covered by a condom.

c. Insert the probe (probe can be inserted by the woman for her comfort).

d. Guide the probe in the anterior fornix of the vagina.

e. Obtain a sagittal long-axis view of the entire endocervical canal.

f. Withdraw the probe until the image is blurred, and reapply just enough pressure to restore the image (to avoid excessive pressure on the cervix, which can elongate it).

g. Enlarge the image so that the cervix occupies at least $2 / 3$ of the screen, and both external and internal ossa are seen. 
h. Measure the cervical length from the internal to the external os along the endocervical canal. If the cervix is curved then trace the canal or use the sum of 2 straight lines that follow the curve of canal.

i. Obtain at least three measurements, and record the shortest best measurement in millimeters.

j. Apply transfundal pressure for 15 seconds, and record cervical length again at least 3 times, recording best measurement.

k. Entire examination should last at least 5 minutes; record only the shortest best cervical length obtained for clinical management.

CL measured by TVU seems to predict preterm delivery in asymptomatic low-risk women as well as those with symptoms of threatened preterm labor [8]. In low-risk pregnant women, mean CL at 14-30 weeks of gestation varies from 35 to $4 \mathrm{~mm}$, with the 10 th percentile being $25 \mathrm{~mm}$ and 90 th percentile being $50 \mathrm{~mm}$ [8]. In asymptomatic women after 30 gestational weeks, the cervix physiologically shortens and CL less than $25 \mathrm{~mm}$ does not indicate preterm labor [9]. It seems that initial screening for preterm delivery should start between 18 and 22 weeks of gestation, because in most women who deliver before 37 weeks a short cervix is detected at that time [8]. In singletons with prior spontaneous preterm birth, serial TVU CL screening is recommended between 16 and $236 / 7$ weeks [9]. In the high risk women, detection of CL less than $25 \mathrm{~mm}$, before 18 weeks, has a positive predictive value of $70 \%$ for preterm delivery before 35 weeks of gestation [10]. Funneling is defined as the opening of the internal cervical os and has good predictive value of PTB. In a study of high-risk women moderate (25\%-50\%) and severe $(>50 \%)$ funneling of the cervix was associated with a high ( $\geq 50 \%$ ) likelihood of PTB [10]. The presence of funneling in a short cervix $(<25 \mathrm{~mm})$ increases the sensitivity of predicting PTB from $61 \%$ (CL $<25 \mathrm{~mm}$ alone) to $74 \%$ [11]. In contrast, in a patient with normal CL detection of funneling does not change the risk of PTB [12].

3D ultrasound was first developed by Olaf von Ramm and Stephen Smith in 1987 [13]. In 3D ultrasound, sound waves are sent at different angles and returning echoes are processed by a computer program which reconstructs a three dimensional volume image $[13,14]$. Recently, TV 3D ultrasound has been used in evaluating uterine cervix simultaneously in three imaging planes: sagittal, transverse and coronal, whereas information from 2D ultrasound on vascularization and blood flow is restricted to a single plane. Some authors suggest that 2D TVS seems to be ineffective in defining the sagittal plane of cervix due to differences in CL measurement results [15-17]. Bega et al. [17] concluded that 3D US offers a more complete assessment of the cervix and their canal than 2D US and can reflect cervical morphology better. Another advantage of 3D US is providing more accurate volume measurements than 2D US [18]. The Virtual Organ Computer-aided Analysis imaging program (VOCAL) is a software which is integrated into the 3D ultrasound system. It is used to calculate cervical volume and power Dopler flow indices from the multiplanar views of the cervix. The technique allows to calculate vascularization index (VI), flow index (FI) and vascularization flow index (VFI). The technique of performing 3D US VOCAL is similar to a 2D technique. When a satisfactory grey-scale image of the cervix with internal os, cervical canal and external oswill be obtained concurrently, the system can be switched into the power Doppler mode and after that into the 3D mode. The duration of the volume evaluation depends on the dimensions of the 3D sector and usually lasts 15-20 seconds [19]. A few authors noted that during manual drawing of the cervical contour some difficulties may appear, because demarcation between the cervix and the lower uterine segment is not clear. Sometimes it can also be difficult to separate the cervix from the vaginal tissue [20,21]. Rovas et al. [22] present reference values for cervical volume and blood flow indices as assessed by 3D power Doppler ultrasound from 17 to 41 gestational weeks, which might be highly beneficial in clinical practice.

\section{Elastography}

Elastography is a modern method useful in assessing the biomechanical properties of tissues. This is an objective based on an ultrasound imaging method which allows a visualization of differences in the consistency of neighboring tissue components. Density of the tissues determines their susceptibility to deformation, which occurs as a result of displacement of tissue structures under compression of ultrasound probe. The differences in tissue strain are presented as a color map, where purple corresponds to the hardest structures while blue, green, yellow and red match softer consistency. So far, elastography has been used in the diagnosis of breast tumors [23], thyroid gland [24], prostate [25], lymph nodes [26] and in detecting focal and diffuse liver diseases [27]. In recent years, the method has also been used in obstetrics and gynecology [28-32].

In obstetrics elastography can be a valuable source of clinically relevant information on the structure of the cervix. During pregnancy the adaptive physiological changes of the cervix make it more flexible to face steady growth of intrauterine pressure resulting from the growth of the fetus. Evaluation of the cervix in normal pregnancy showed that a stiffness reduction occurs gradually throughout pregnancy, as opposed to shortening of the cervix observed only in the third trimester [33,34]. Labor is preceded by the dynamic changes in the microstructure of the cervix. The tissue becomes softer and more susceptible to stretching. The underlying mechanism of this phenomenon is the dispersion of collagen fibers and their gradual depolymerization associated with increased activity of matrix metalloproteinases and a decrease in the tissue inhibitors of these enzymes in the extracellular matrix. It results in an increase in osmotic pressure in the tissue of the cervix with its hydration and softening [35]. These phenomena occur before the start of uterine contractions. When cervical ripening begins too early, the process can lead to preterm delivery. 
The main limitation of cervical elastography results from the lack of standardization of the force with which the operator obstructs the tissues with the vaginal probe [36]. It has a significant impact on the interpretation of the ultrasound image. Currently used elastography systems are not equipped with force sensors, which would render the method more objective [37]. It should be taken into account that because of the anatomical characteristics of an organ, its deformation depends on the position of the transducer. If the same force is applied, tissues closer to the probe will deform more than those that are further away and are devoid of direct pressure. The studies conducted so far have shown significant differences of consistency between areas of the cervix, while the studies were not focused on the measurement of the absolute value of the biomechanical properties of the tissue.

Various methods of interpretation of elastogram of the cervix have been applied. Thomas [30] and Yamaguchi [38] determined an 'elasticity tissue quotient', which expressed the ratio of each color observed in the elastogram. They used a 'slight pressure' technique to induce cervix deformations. A similar technique based on repeated mild probe compressions was applied by Khalil et al. [39]. The researchers found that the strain of the cervix is the greatest in the area of the external os and decreases with the distance from the probe. It seems that the smaller tissue deformation is rather a result of the use of less force than the actual density and stiffness of the cervix. A greater standardization of the test was obtained when repetitive one second cycles of compression and decompression were applied under the control of an indicator of compression magnitude installed in the ultrasound system [29]. The study included 112 pregnant women at different gestational age who were tested twice by one operator. In 50 cases, an additional test was performed by a second operator, without knowledge of previous results, and the two measurements were compared. The resulting data showed a significant reproducibility of the results with the exception of the area corresponding to the external os and the anterior cervical lip, where the vaginal probe tip is situated. This may prove that the soft tissues, such as the cervix, can be easily deformed by the probe and only the assessment of structures further away, without direct pressure can provide reliable data helpful in the clinical management. Another method of cervical elastography proposed by Fruscalzo et al. [40] was based on maximum compression of the anterior lip untill the posterior lip was displaced. The authors demonstrated that this method is more reliable and reproducible in comparison with the use of lower pressure.

In recent years, several studies have been performed in which elastography was used to determine the success of labor induction and risk of preterm birth assessment. In the study by Świątkowska-Freund \& Preis [41] 20 pregnant women prepared for induction of labor were tested. Color differences between the various areas of the cervix reflecting the difference in the consistency of tissue were correlated with numerical scale.
Reference, as the hardest, was a posterior lip of the cervix. Then, the data were compared with the assessment of the cervix in the Bishop score as well as ultrasound measurement of cervical length and internal os and correlated with successful induction of labor. The authors found a statistically significant $(\mathrm{p}=0.0004)$ correlation between the internal os consistency and the induction effect and a negative correlation between consistency of both internal, external os, and the Bishop scale. In 2011 the same researchers described a different way of elastography interpretation. They applied a so-called elastography index where the five-color scale, reflecting differences in the consistency of the cervical tissue was changed into a numerical scale [28]. No additional pressure was applied to the cervix. Only the deformation due to breathing movements and pulsation of blood vessels was detected. Twenty-nine pregnant women expecting induction of labor were examined. There was no statistically significant correlation between the elastography index and any cervical area, the Bishop score or the length of the cervix. The average elastography index around the internal os was significantly higher $(\mathrm{p}=0.024)$ in women with successful labor induction in comparison with women with a failed induction.

Hernandez-Andrade and co-workers aimed to determine cervical stiffness in pregnant women [37]. In 262 pregnant women between 8 and 40 weeks cervical strain was determined in the sagittal and cross-sectional plane under the control of compression volume ratio. The results confirmed the previous data, which reported the structure of the cervical canal and deeper structures as softer than the area of the external os. In addition, the authors demonstrated the decrease in the hardness of the cervix, with its shortening and increasing gestational age. The work of Fuchs et al. [42] showed a statistically significant correlation between the consistency of the front lip of the cervix and its length in 59 women between 28th and 39th weeks of gestation.

Wozniak et al. [43] conducted a study in a group of 333 healthy women with a low risk of preterm delivery. Elastography and cervical length measurement were performed between 18 th and $22 \mathrm{nd}$, and at 30 th week of gestation during routine ultrasound examinations. Thirty-five evaluated women delivered prematurely. Elastography of the internal os showed that preterm delivery occurred significantly more often in women, in whom the cervix was assessed as soft or medium soft (red and yellow) compared to women with cervix assessed as a medium hard or hard (blue and purple). The authors found a statistically significant positive correlation between the stiffness of the internal os and cervical length assessed in 18th-22th gestational week. There was also a significant negative correlation between the stiffness of the internal os and the degree of shortening of the cervix between the second and the third trimester. Funneling at 30 weeks was observed significantly more frequently in women with a 'soft' structure of the internal os in the second trimester.

The use of elastography in preterm birth risk assessment was described by Świątkowska-Freund et al. [44]. Elastography 
and physical examination carried out by two independent investigators were performed in a group of 44 patients with premature contractions before 37 weeks of gestation. Elastography index of the internal opening of the cervix showed a significant correlation with the occurrence of preterm delivery $(p<0.001)$ and the time dividing the onset of labor and the patient evaluation $(p<0.001)$. A similar significant correlation was found with respect to the length of the cervical canal and the risk of preterm birth and the time from the test to delivery.

Elastography gives an opportunity to evaluate the consistency of the tissue around the internal opening of the cervix which is not available in the digital vaginal examination. It is a noninvasive, easy and reproducible method. Elastography allows identifying patients with an increased risk of preterm birth in asymptomatic women. The changes observed in elastography may precede other ultrasound symptoms, such as funneling or shortening of the cervix, and the clinical symptoms of preterm labor. The correlation between flexibility of internal os of the cervix and its length makes elastography a valuable examination which may be complementary to currently used techniques of cervix imaging in terms of predicting preterm delivery.

\section{Conclusion}

The application of new ultrasonographic methods for the evaluation of cervical uterus (VOCAL and elastography), and risk assessment could allow selection, within pregnant women with the activity of premature contractions, of patients with the highest risk of preterm delivery as well as providing early care and treatment for them.

\section{References}

1. Davidoff MJ, Dias T, Damus K, Russell R, Bettegowda VR, et al. (2006) Changes in the gestational age distribution among U.S. singleton births: impact on rates of late preterm birth, 1992 to 2002. Semin Perinatol 30(1): 8-15.

2. Peaceman AM, Andrews WW, Thorp JM, Cliver SP, Lukes A, et al. (1997) Fetal fibronectin as a predictor of preterm birth in patients with symptoms: a multicenter trial. Am J Obstet Gynecol 177(1): 13-18.

3. Crane JM, Van den Hof M, Armson BA, Liston R (1997) Transvaginal ultrasound in the prediction of preterm delivery: singleton and twin gestations. Obstet Gynecol 90(3): 357-363.

4. Goldberg J, Newman RB, Rust PF (1997) Interobserver reliability of digital and endo vaginal ultrasonographic cervical length measurements. Am J Obstet Gynecol 1774: 853-858.

5. Hernandez-Andrade E, Romero R, Ahn H, Hussein Y, Yeo L, et al. (2012) Transabdominal evaluation of uterine cervical length during pregnancy fails to identify a substantial number of women with a short cervix. J MaternFetal Neonatal Med 25(9): 1682-1689.

6. Owen J, Yost N, Berghella V, Thom E, Swain M, et al. (2001) Mid-trimester endovaginalsonography in women at high risk of spontaneous preterm birth. JAMA 286(11): 1340-1348.

7. Berghella V, Bega G (2008) Ultrasound evaluation of the cervix. In: Callen PW (Ed.), Ultrasonography in Obstetrics and Gynecology. Saunders Elsevier, Philadelphia, USA, pp. 698-720.

8. Crane JMG, Hutchens D (2008) Trans vaginalsonographic measurement of cervical length to predict preterm birth in asymptomatic women at increased risk: a systematic review. Ultrasound Obstet Gynecol 31(5): 579-587.

9. Orzechowski KM, Boelig RC, Berghella V (2016) Cervical Length Screening in Asymptomatic Women at High Risk and Low Risk for Spontaneous Preterm Birth. ClinObstet Gynecol 59(2): 241-251.

10. Berghella V, Baxter JK, Hendrix NW (2013) Cervical assessment by ultrasound for preventing preterm delivery. Cochrane Database Syst Rev 31: CD007235.

11. Berghella V, Daly SF, Tolosa JE, DiVito MM, Chalmers R, et al. (1999) Prediction of preterm delivery with transvaginal ultrasonography of the cervix in patients with high risk pregnancies: does cerclage prevent prematurity? Am J Obstet Gynecol 181(4): 809-815.

12. Berghella V, Roman A (2005) Does funneling increase the incidence of preterm birth in women with normal cervical length? Am J Obstet Gynecol 193: S147.

13. Ramm O, Smith S, inventors (1987) Three dimentional imaging system USA, 4694434, assignee.

14. Michailidis G, Papageorgiou P, Economides D (2002) Assessment of fetal anatomy in the first trimester using two and three dimentional ultrasound. British Journal of Radiology 75(891): 215-219.

15. Severi MF, Bocchi C, Florio P, Picciolini E, D’Aniello G, et al. (2003) Comparison of two-dimensional and three-dimensional ultrasound in the assessment of the cervix to predict preterm delivery. Ultrasound Med Biol 29: 1261-1265.

16. Towner D, Boe N, Lou K, Gilbert M (2004) Cervical length measurements in pregnancy are longer when measured with three-dimensional transvaginal ultrasound. J Matern Fetal Neonatal Med 16: 167-170.

17. Bega G, Lev-Toaff A, Kuhlman K (2000) Three-dimensional multiplanartransvaginal ultrasound of the cervix in pregnancy. Ultrasound Obstet Gynecol 16(4): 351-358.

18. Kurjak A, Merce LT, Badreldeen A (2008) 3D Power Doppler in the study of fetal and maternal angiogenesis and vasculogenesis. In: Kurjak A, Chervenak FA (Eds.), Donald school textbook of Ultrasound in Obstetrics and Gynecology. ( $2^{\text {nd }}$ edn), Jaypee brothers medical publishers, India, pp. 433-451.

19. Basgul A, Kavak ZN, Bakirci N (2006) Intra- and interobserver agreement on cervical volume and flow indices during pregnancy using transvaginal 3-dimensional ultrasonography and Doppler angiography. Int J Fertil Womens Med 51: 256-261.

20. Hoesli IM, Surbek DV, Tercanli S, Holzgreve W (1999) Three dimensional volume measurement of the cervix during pregnancy compared to conventional 2D-sonography. Int J Gynaecol Obstet 64(2): 115-119.

21. Rozenberg P, Rafii A, Senat MV, Dujardin A, Rapon J, et al. (2003) Predictive value of two-dimensional and three-dimensional multiplanar ultrasound evaluation of the cervix in preterm labor. J Matern Fetal Neonatal Med 13(4): 237-241.

22. Rovas L, Sladkevicius P, Strobel E, Valentin L (2006) Reference data representative of normal findings at three-dimensional power Doppler ultrasound examination of the cervix from 17 to 41 gestational weeks. Ultrasound Obstet Gynecol 28: 761-767.

23. Gheonea IA, Stoica Z, Bondari S (2011) Differential diagnosis of breast lesions using ultrasound elastography. Indian J Radiol Imaging 21(4): 301-305.

24. Bhatia KS, Tong CS, Cho CC, Yuen EH, Lee YY, et al. (2012) Shear wave elastography of thyroid nodules in routine clinical practice: preliminary observations and utility for detecting malignancy. Eur Radiol 22(11): 2397-2406.

25. Dudea SM, Giurgiu CR, Dumitriu D, Chiorean A, Ciurea A, et al. (2011) Value of ultrasound elastography in the diagnosis and management of prostate carcinoma. Med Ultrason 13(1): 45-53. 
26. Wojcinski S, Dupont J, Schmidt W, Cassel M, Hillemanns P (2012) Realtime ultrasound elastography in 180 axillary lymph nodes: elasticity distribution in healthy lymph nodes and prediction of breast cancer metastases. BMC Med Imaging 12: 35.

27. Chen S, Sanchez W, Callstrom MR, Gorman B, Lewis JT, et al. (2013) Assessment of liver viscoelasticity by using shear waves induced by ultrasound radiation force. Radiology 266(3): 964-970.

28. Swiatkowska-Freund M, Preis K (2011) Elastography of the uterine cervix: implications for success of induction of labor. Ultrasound Obstet Gynecol 38(1): 52-56

29. Molina FS, Gómez LF, Florido J, Padilla MC, Nicolaides KH (2012) Quantification of cervical elastography: a reproducibility study. Ultrasound Obstet Gynecol 39(6): 685-689.

30. Thomas A (2006) Imaging of the cervix using sonoelastography. Ultrasound Obstet Gynecol 28(3): 356-357.

31. Thomas A, Kümmel S, Gemeinhardt O, Fischer T (2007) Real-time sonoelastography of the cervix: tissue elasticity of the normal and abnormal cervix. Acad Radiol 14(2): 193-200.

32. Ami O, Lamazou F, Mabille M, Levaillant JM, Deffieux X, et al. (2009) Real-time transvaginal elastosonography of uterine fibroids. Ultrasound Obstet Gynecol 34: 486-488.

33. Parra-Saavedra M, Gómez L, Barrero A, Parra G, Vergara F, et al. (2011) Prediction of preterm birth using the cervical consistency index. Ultrasound Obstet Gynecol 38(1): 44-51.

34. Badir S, Mazza E, Zimmermann R, Bajka M (2013) Cervical softening occurs early in pregnancy: characterization of cervical stiffness in 100 healthy women using the aspiration technique. Prenat Diagn 33(8): 737-741.

35. Stygar D, Wang H, Vladic YS, Ekman G, Eriksson H, et al. (2002) Increased level of matrix metalloproteinases 2 and 9 in the ripening process of the human cervix. Biol Reprod 67: 889-894.
36. Fruscalzo A, Schmitz R (2013) Reply. Ultrasound Obstet Gynecol 41: 712-714.

37. Hernandez-Andrade E, Hassan SS, Ahn H, Korzeniewski SJ, Yeo L, et al. (2013) Evaluation of cervical stiffness during pregnancy using semiquantitative ultrasound elastography. Ultrasound Obstet Gynecol 41(2): 152-161.

38. Yamaguchi S, Kamei Y, Kozuma S, Taketani Y (2007) Tissue elastography imaging of the uterine cervix during pregnancy. J Med Ultrasonics 34(4): 209-210.

39. Khalil MR, Thorsen P, Uldbjerg N (2013) Cervical ultrasound elastography may hold potential to predict risk of preterm birth. Dan Med J 60(1): A4570.

40. Fruscalzo A, Steinhard J, Londero AP, Fröhlich C, Bijnens B, et al. (2013) Reliability of quantitative elastography of the uterine cervix in at-term pregnancies. J Perinat Med 41(4): 421-427.

41. Swiatkowska-Freund M, Preis K (2010) New methods of ultrasonographic assessment of uterine cervix before an induction of labour. Gin Pol Med Project 3: 9-15.

42. Fuchs T, Woytoń R, Pomorski M, Wiatrowski A, Slejman N, et al. (2013) Sonoelastography of the uterine cervix as a new diagnostic tool of cervical assessment in pregnant women - preliminary report. Ginekol Pol 84: 12-16.

43. Wozniak S, Czuczwar P, Szkodziak P, Milart P, Wozniakowska E, et al. (2014) Elastography in predicting preterm delivery in asymptomatic, low-risk women: a prospective observational study. BMC Pregnancy Childbirth 14: 238.

44. Swiatkowska-Freund M, Traczyk-Łoś A, Preis K, Łukaszuk M, Zielińska K (2014) Prognostic value of elastography in predicting premature delivery. Ginekol Pol 85: 204-207.

This work is licensed under Creative

Commons Attribution 4.0 Licens

DOI: 10.19080/JGWH.2018.08.555733

\section{Your next submission with Juniper Publishers will reach you the below assets}

- Quality Editorial service

- Swift Peer Review

- Reprints availability

- E-prints Service

- Manuscript Podcast for convenient understanding

- Global attainment for your research

- Manuscript accessibility in different formats

( Pdf, E-pub, Full Text, Audio)

- Unceasing customer service

Track the below URL for one-step submission https://juniperpublishers.com/online-submission.php 